\title{
Combined effect of propranolol, vincristine and bevacizumab on HUVECs and BJ cells
}

\author{
MĂDĂLINA BOTA ${ }^{1 *}$, EVA FISCHER-FODOR $^{2,3^{*}}$, OVIDIU-VASILE BOCHIȘ $^{4}$, MIHAI CENARIU $^{5}$, \\ GHEORGHE POPA $^{1}$, CRISTINA LUCIA BLAG ${ }^{1}$ and ALEXANDRU TĂTARU ${ }^{6}$ \\ ${ }^{1}$ Department of Pediatrics, University of Medicine and Pharmacy 'Iuliu Hațieganu', 400012 Cluj-Napoca; \\ ${ }^{2}$ Tumor Biology Department, The Oncology Institute 'I. Chiricuță', 400015 Cluj-Napoca; ${ }^{3}$ Medfuture-Research Center for \\ Advanced Medicine, University of Medicine and Pharmacy 'Iuliu Hațieganu', 400012 Cluj-Napoca; \\ ${ }^{4}$ Department of Medical Oncology, The Oncology Institute 'I. Chiricuță', 400015 Cluj-Napoca; \\ ${ }^{5}$ Biotechnology Research Center, University of Agricultural Science and Veterinary Medicine, 400374 Cluj-Napoca; \\ ${ }^{6}$ Department of Dermatology, University of Medicine and Pharmacy 'Iuliu Hațieganu', 400012 Cluj-Napoca, Romania
}

Received March 25, 2018; Accepted September 14, 2018

DOI: $10.3892 /$ etm.2018.6925

\begin{abstract}
Infantile hemangioma is one of the most common benign tumors affecting children, with $\sim 10-15 \%$ requiring medical treatment. These tumors consist of endothelial cells and stromal components, including fibroblasts, pericytes and mast cells. Effects of propranolol treatment in combination with bevacizumab or vincristine on cell growth were compared in the current study using human umbilical vein endothelial cells (HUVECs) and BJ human normal fibroblasts (BJs) to determine potential synergic effects in vitro. Inhibition of cell growth was investigated using MTT assays and cytotoxicity of the drugs in various combinations was expressed as half inhibitory concentration $\left(\mathrm{IC}_{50}\right)$. Apoptosis was investigated using flow cytometry, with Alexa Fluor 488 and propidium iodide. Propranolol inhibited BJ and HUVEC growth in a dose-dependent manner, with increased response observed in BJs (IC50, 148,32 $\mu \mathrm{g} / \mathrm{ml}$; standard error $\log \mathrm{IC} 50,0.07$ ). Treatment with vincristine induced the strongest growth inhibition in HUVECs (IC50, 17,89 $\mu \mathrm{g} / \mathrm{ml}$; standard error $\log$ IC50, 0.07) and BJs (IC50, 24,81 $\mu \mathrm{g} / \mathrm{ml}$; standard error $\log$ IC50, 0.08) compared with propranolol (HUVEC IC50, 81,94 $\mu \mathrm{g} / \mathrm{ml}$; standard error log IC50, 0.06; BJ-IC50, $148,32 \mu \mathrm{g} / \mathrm{ml}$; standard error $\log \mathrm{IC} 50,0.07)$ or bevacizumab (HUVEC IC50 96,91 $\mu \mathrm{g} / \mathrm{ml}$; standard error log IC50, 0.06; BJ IC50, 182,70 $\mu \mathrm{g} / \mathrm{ml}$; standard error log IC50, 0.09) alone.
\end{abstract}

Correspondence to: Dr Mădălina Bota, Department of Pediatrics, University of Medicine and Pharmacy 'Iuliu Hațieganu', 8 Victor Babeș Street, 400012 Cluj-Napoca, Romania

E-mail: madalina.bota@umfcluj.ro

${ }^{*}$ Contributed equally

Key words: infantile hemangioma, human umbilical vein endothelial cells, fibroblasts, propranolol, vincristine, bevacizumab
Bevacizumab was the weakest cytotoxic agent. Combination treatment of vincristine with bevacizumab induced the highest levels of apoptosis in HUVECs compared with all other treatments and triple-drug therapy induced the levels of apoptosis in BJs. Single treatment with vincristine, propranolol or bevacizumab induced apoptosis in BJs and HUVECs. In BJs, triple treatment exhibited the greatest influence on apoptosis, compared with single and dual treatments and in HUVECs, vincristine and bevacizumab combination treatment induced apoptosis to the highest level. The present study offers novel perspectives in drug repurposing studies for the three drugs, particularly in diseases where the pathogenesis is based on healthy endothelial cell proliferation, including hemangiomas.

\section{Introduction}

Infantile hemangioma is one of the most common benign tumors affecting children, occurring in 4-10\% of all infants and $\sim 10-15 \%$ require medical treatment $(1,2)$. The tumors consist of endothelial cells and stromal components, including fibroblasts, pericytes and mast cells $(3,4)$. Following the proliferation phase, endothelial cells are replaced with adipocytes, which subsequently determine the involution of the tumor (5).

Before 2008, various therapies have been established to treat infantile hemangioma, including cortisone, vincristine, interferon- $\alpha$ and lasertherapy; however, these therapeutic treatments have been demonstrated to be associated with potentially severe adverse side effects (5). Following reports on antiproliferative effects of propranolol by Léauté-Labrèze et al (6) in 2008, various studies have been performed investigating the mechanisms by which propranolol induces the involution of hemangiomas $(1,2)$. Propranolol is a non-selective $\beta$-blocker used worldwide as the first-line therapy for hemangiomas (5). Several mechanisms, including vasoconstriction, blocking of proangiogenic signals and induction of apoptosis, have been suggested as underlying mechanisms (2).

Vincristine is a chemotherapeutical agent that inhibits endothelial cell growth by blocking mitosis and the formation of 
microtubules by direct cytotoxicity (7). Furthermore, vincristine is used as a second or third-line therapeutical agent in life-threatening situations, including severe bleeding, blocked airway or Kassabach Meritt syndrome, or in steroid-resistant and steroid-dependent hemangiomas (8).

It has been established that the vascular endothelial growth factor (VEGF) and basic fibroblastic growth factor (bFGF) stimulate cell proliferation, which subsequently results in the growth of hemangiomas (5). A well-studied antiangiogenic treatment is bevacizumab, a humanized monoclonal antibody that binds to VEGF and inhibits angiogenesis (9). Bevacizumab is used in treating certain types of cancer, including colon or lung cancer, affecting adults (9). Treatment of patients with hemangiomas has not been studied extensively (10).

The aim of the present study was to assess effects of propranolol on human umbilical vein endothelial cells (HUVECs) and BJ human normal fibroblasts (BJs). Furthermore, the efficacy of vincristine and bevacizumab in combination with propranolol was assessed. To investigate the activity of the drugs and various drug combinations, the present study established an in vitro model consisting of normal fibroblasts and HUVECs to mimic the primary source of hemangiomas. Effects of propranolol, a clinically approved hemangioma treatment, on cell growth were compared with bevacizumab, aVEGF inhibitor, and vincristine, a mitosis inhibitor. Effects of various treatment combinations were evaluated to determine potential synergic effects.

\section{Materials and methods}

Cell cultures. BJs (CRL-2522) were purchased from the American Type Culture Collection (Manassas, VA, USA) and HUVECs were provided by Dr. Olga Soritau, from the Oncology Institute 'I. Chiricuță' (Cluj-Napoca, Romania) established from a primary source at the European Collection of Authenticated Cell Cultures (Salisbury, UK).

BJs were cultured at $37^{\circ} \mathrm{C}$ in a $5 \% \mathrm{CO}_{2}$ incubator in Eagle's Minimum Essential medium (MEM, Sigma-Aldrich; Merck KGaA, Darmstadt, Germany) and HUVECs were cultured in Endothelial Cell Growth medium (ECG, Cell Applications, Inc., San Diego, CA, USA); media were supplemented with $10 \%$ fetal calf serum (Sigma-Aldrich; Merck KGaA).

Cells were trypsin-digested at $75-85 \%$ subconfluency and seeded at $12 \times 10^{3}$ cells/well in 96-well plates with $190 \mu 1$ media (as described above). BJs were passaged 9-12 times and HUVECs were passaged 18-20 times. Passages were performed twice a week and no replacement of media was performed in between.

Drug preparations. Vincristine sulfate was purchased from Sindan Pharma SRL (Sindovin; Bucharest, Romania). A total of $1 \mathrm{mg}$ vincristine (excipient, anhydrous lactose monohydrate) was dissolved in $500 \mu \mathrm{l}$ ultrapure water (Lonza Group, Ltd., Basel, Switzerland) to obtain a 2,000 $\mu \mathrm{g} / \mathrm{ml}$ stock and serial dilutions $(1,000,750,500,250,125,62.5,32$ and $16 \mu \mathrm{l} / \mathrm{ml})$ were prepared with PBS. Concentrations in the culture medium were $100,50,25,12.5,6.25,3.12,1.6$ and $0.8 \mu \mathrm{g} / \mathrm{ml}$.

Propranolol chloral hydrate was purchased from Sintofarm SA (Propranolol; Bucharest, Romania). A total of $40 \mathrm{mg}$ propranolol (excipients, lactose monohydrate, microcrystalline cellulose and cornstarch) was dissolved in $1,000 \mu \mathrm{l}$ of ultrapure water to obtain a $40 \mathrm{mg} / \mathrm{ml}$ stock. Serial dilutions between $2,000-15.6 \mu 1 / \mathrm{ml}(2,000,1,000,500,250,125,62.5,31.25$ and $15.6 \mu \mathrm{l} / \mathrm{ml}$ ) were prepared in PBS. In vitro drug concentrations were extrapolated from in vivo doses based on previous studies (11-13).

Bevacizumab was purchased from Roche Applied Science (Avastin; Penzberg, Germany) and provided as a $25 \mathrm{mg} / \mathrm{ml}$ solution in water, containing excipients including trehalose dihydrate, sodium phosphate and polysorbate 20 . Serial dilutions were prepared using the $25 \mathrm{mg} / \mathrm{ml}$ stock solution to obtain final concentrations between $19.5-2,500 \mu \mathrm{g} / \mathrm{ml}$ in cell culture medium.

Various propranolol concentrations were combined with a subcytotoxic concentration of vincristine and bevacizumab. All aforementioned propranolol concentrations were combined with subcytotoxic $10 \mu \mathrm{g} / \mathrm{ml}$ vincristine or $100 \mu \mathrm{g} / \mathrm{ml}$ bevacizumab.

Cytotoxicity measurements. For single drug treatments, medium was removed from the wells and replaced with $10 \mu \mathrm{l}$ drug stock in PBS plus $190 \mu$ l of ECG for HUVECs and MEM for BJs, respectively. For combination treatments, medium was replaced with $10 \mu \mathrm{l}$ of each drug stock solution in PBS plus 180 or $170 \mu 1$ medium for dual or triple drug combinations, respectively. When cells were adherent to 96 -well plates, drug treatments were administered for $24 \mathrm{~h}$ at $37^{\circ} \mathrm{C}$ as follows: in pairs; propranolol with vincristine, propranolol with bevacizumab and vincristine with bevacizumab; or with all three administered together. Cytotoxicity was then measured. Assays were performed in triplicate with untreated, viable cells used as negative controls. Blanks were based on cell culture media and were recorded in parallel.

Following incubation with the treatment, plates were subjected to MTT analyses (Sigma-Aldrich; Merck KGaA) according to a previously described protocol (14). Formazan crystals were dissolved in $150 \mu 1$ dimethyl sulfoxide (Titolchimica, Pontecchio Polesine, Italy) and the intensity of coloration was measured spectrophotometrically, at $570 \mathrm{~nm}$. Coloration is directly proportional to the number of living cells and resulting absorbance values were used to determine half inhibitory concentration $\left(\mathrm{IC}_{50}\right)$ values from dose-response curves usingGraph Pad Prism 5 (GraphPad Software, Inc., La Jolla, CA, USA).

Apoptosis induction. Apoptotic and necrotic cell counts in treated BJs and HUVECs were determined by flow cytometry using the Alexa Fluor 488 Annexin V/propidium iodide (PI) Apoptosis kit (Invitrogen; Thermo Fisher Scientific, Inc.) following a previously described method (15). BJs and HUVECs were incubated in six-well plates at $2 \times 10^{5}$ cells $/ \mathrm{ml}$ in $3 \mathrm{ml}$ media for $24 \mathrm{~h}$ and treated with the following drugs for $24 \mathrm{~h}: 50 \mu \mathrm{g} / \mathrm{ml}$ propranolol, $10 \mu \mathrm{g} / \mathrm{ml}$ vincristine, $50 \mu \mathrm{g} / \mathrm{ml}$ bevacizumab, propranolol $(50 \mu \mathrm{g} / \mathrm{ml})$ plus vincristine $(10 \mu \mathrm{g} / \mathrm{ml})$, propranolol $(50 \mu \mathrm{g} / \mathrm{ml})$ plus bevacizumab $(50 \mu \mathrm{g} / \mathrm{ml})$, vincristine $(10 \mu \mathrm{g} / \mathrm{ml})$ plus bevacizumab $(50 \mu \mathrm{g} / \mathrm{ml})$ and propranolol $(50 \mu \mathrm{g} / \mathrm{ml})$ plus vincristine $(10 \mu \mathrm{g} / \mathrm{ml})$ plus bevacizumab $(50 \mu \mathrm{g} / \mathrm{ml})$. Untreated cells were used as a negative control. Following treatment, cells were harvested, washed with Binding Buffer provided by the 
A

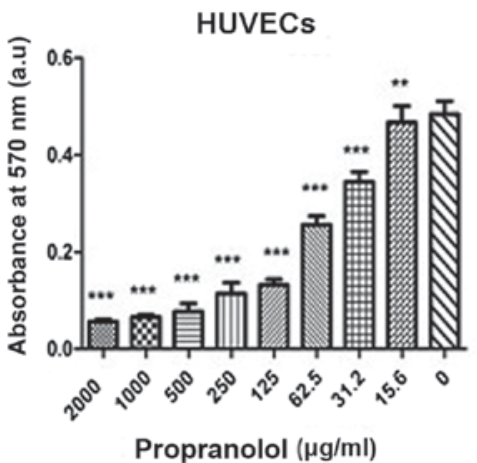

C

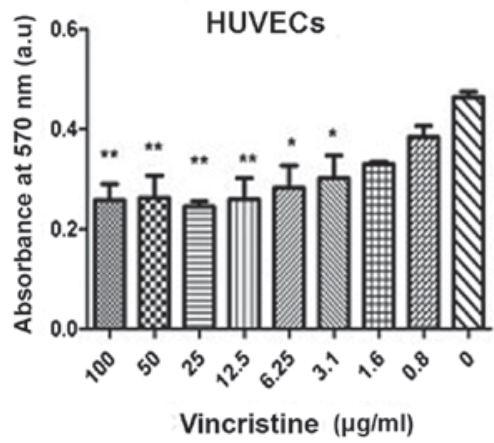

E

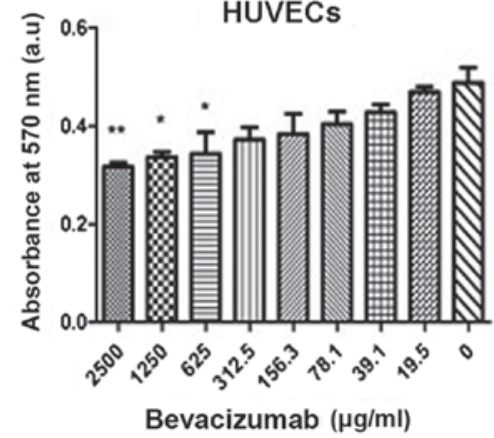

B

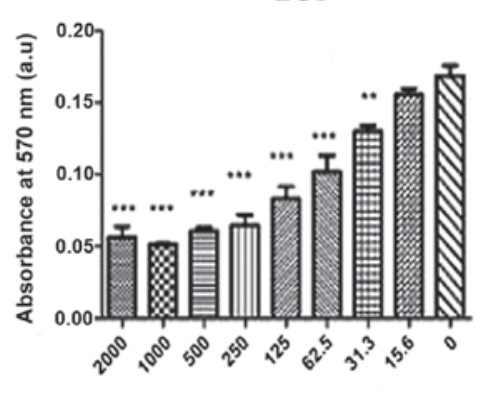

Propranolol $(\mu \mathrm{g} / \mathrm{ml})$
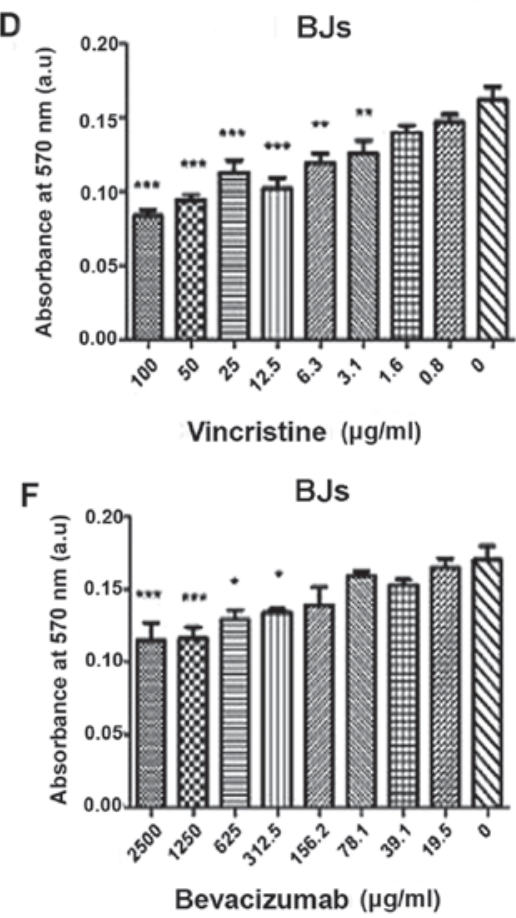

Figure 1. Inhibitory effect of propranolol, vincristine and bevacizumab in HUVECs and BJs. Cell viability determined by MTT assay is presented as a function propranolol in (A) HUVECs and (B) BJs, vincristine in (C) HUVECs and (D) BJs, and bevacizumab in (E) HUVECs and (F) BJs. "P<0.05; ** P<0.01; and ${ }^{* * *} \mathrm{P}<0.001$ vs. untreated $(0 \mu \mathrm{g} / \mathrm{ml})$. HUVEC, human umbilical vein endothelial cell; BJ, CRL-2522 human normal fibroblast.

kit, incubated for $15 \mathrm{~min}$ at room temperature with Alexa Fluor 488-labeled Annexin V and PI. Samples were subjected to analysis using the FACS Canto II flow-cytometer (Becton Dickinson; BD Biosciences; Franklin Lakes, NJ, USA). Two experiments were performed per treatment and mean values were determined using FACS Canto software (BD FACS Diva version 6.1; Becton Dickinson; BD Biosciences). AlexaFluor 488-labeled apoptotic cells were identified and analyzed using a 530/30 $\mathrm{nm}$ filter and PI-labeled necrotic cells were detected using a 575/26 nm filter.

Statistical analysis. Statistical analyses were performed using GraphPad Prism5 (GraphPad Software, Inc.). IC values were determined as the mean \pm standard deviation, by performing a non-linear regression analysis on the logarithm of the concentration vs. the normalized absorbance. Each value was determined in triplicate and three independent measurements were performed. Cell growth rates were compared using one-way analysis of variance and Dunnett's multiple comparison test, with untreated cells as reference and using a $95 \%$ confidence interval (CI). For apoptosis evaluation, 10,000 individual single-cell measurements were evaluated and comparisons are based on one-way analysis of variances followed by Bonferroni post-hoc tests using a 95\% CI. Correlation between the number of early apoptotic cells, late apoptotic cells and dead cells was assessed using a nonparametric Spearman correlation with a 95\% CI. P<0.05 was considered to indicate a statistically significant result.

\section{Results}

Cell growth inhibition. In vitro cytotoxicity was determined for propranolol, vincristine and bevacizumab using HUVECs and BJs to determine novel therapeutic strategies. Following treatment with various propranolol concentrations $(15.6-2,000 \mu \mathrm{g} / \mathrm{ml})$, as aforementioned, results revealed that the $\beta$-blocker inhibited growth of BJs and HUVECs in a dose-dependent manner (Fig. 1A and B, respectively). A more marked effect was observed in BJs compared with HUVECs. Vincristine inhibited growth in $>50 \%$ of cell populations for BJs and HUVECS at $100 \mu \mathrm{g} / \mathrm{ml}$ (Fig. 1C and D). Bevacizumab was revealed to be the weakest cytotoxic agent in the 
A

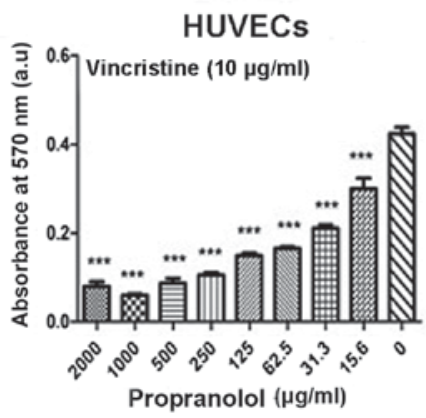

C

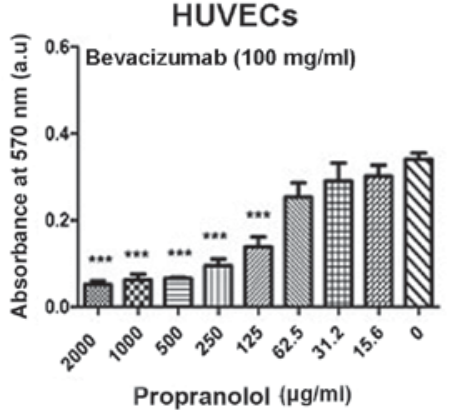

E

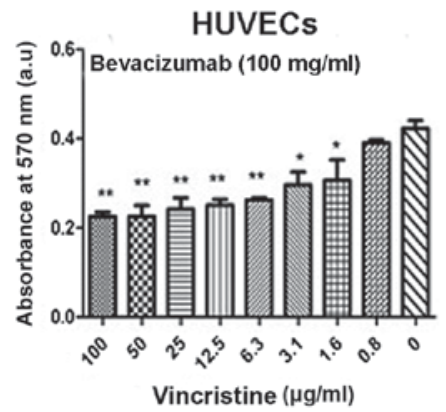

B

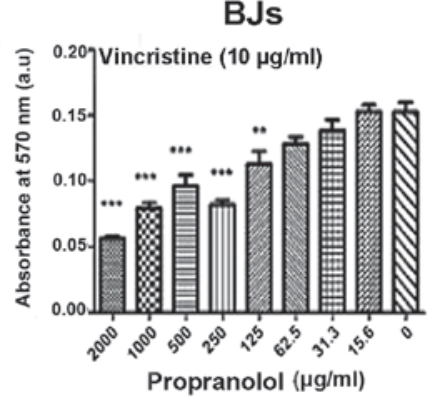

D

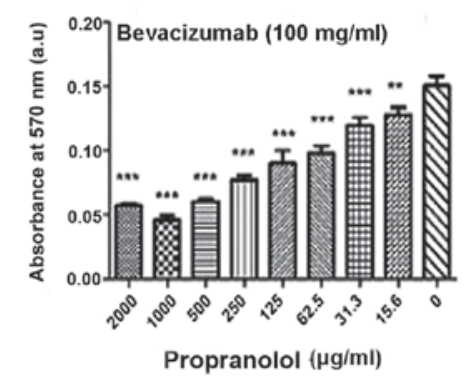

$\mathbf{F}$

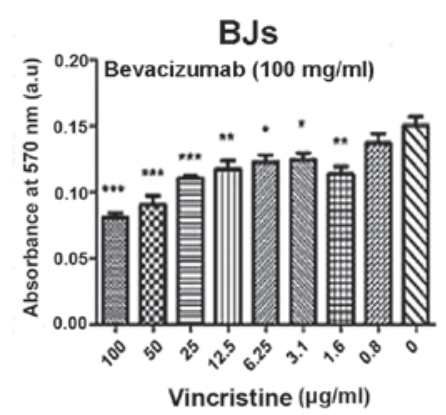

Figure 2. Inhibitory effect of propranolol plus vincristine, propranolol plus bevacizumab and vincristine plus bevacizumab in HUVECs and BJs. Cell viability determined by MTT assay is presented as a function of drug concentration, with varying propranolol plus $10 \mu \mathrm{g} / \mathrm{ml}$ vincristine in (A) HUVECs and (B) BJs, with varying propranolol plus $100 \mathrm{mg} / \mathrm{ml}$ bevacizumab in (C) HUVECs and (D) BJs, and with varying vincristine plus $100 \mathrm{mg} / \mathrm{ml}$ bevacizumab in (E) HUVECs and (F) BJs. ${ }^{*} \mathrm{P}<0.05 ;{ }^{* *} \mathrm{P}<0.01$; and ${ }^{* * *} \mathrm{P}<0.001$ vs. untreated $(0 \mu \mathrm{g} / \mathrm{ml})$. HUVEC, human umbilical vein endothelial cell; BJ, CRL-2522 human normal fibroblast.

tested cell lines compared with propranolol and vincristine (Fig. 1E and F).

In order to investigate effects of combined treatments, various concentrations of propranolol, as aforementioned, were administered in combination with sublethal concentrations of vincristine $(10 \mu \mathrm{g} / \mathrm{ml})$ or bevacizumab $(100 \mu \mathrm{g} / \mathrm{ml})$ to BJs und HUVECs (Fig. 2).

Nonlinear dose-response curves were generated to determine $\mathrm{IC}_{50}$ values for the various drug treatments using BJs and HUVECs (Table I). Decreased $\mathrm{IC}_{50}$ values indicate higher levels of cytotoxicity. In every IC50 value evaluation, the absorbance measurement of the untreated cells served as the reference value for $100 \%$ viability. Therefore on every sigmoidal curve, which generates the IC50 value, measurements correspond to the untreated cells. The results confirmed a significantly increased treatment effect of propranolol when combined with vincristine $(10 \mu \mathrm{g} / \mathrm{ml})$ or bevacizumab $(100 \mu \mathrm{g} / \mathrm{ml})$ compared with the propranolol alone (Table $\mathrm{I}$ ). $\mathrm{IC}_{50}$ values were lower in HUVECs compared with BJs, following treatment with propranolol. Following combination treatment with bevacizumab or vincristine, $\mathrm{IC}_{50}$ values in $\mathrm{BJ}$ s decreased, increasing the cytotoxic treatment effect by 72.35 and $63.74 \%$, respectively.
In comparison, the percentages in HUVECs were lower in combination treatment, the cytotoxic effect was increased only by $19.52 \%$ with bevacizumab and $33.49 \%$ with vincristine. In HUVECs and BJs, triple treatment with propranolol, bevacizumab and vincristine resulted in a decreased $\mathrm{IC}_{50}$ compared with the single propranolol treatment and cytotoxicity increased by 94.78 and $89.55 \%$, respectively (data not shown).

Apoptosis induction. Following $24 \mathrm{~h}$ treatment, apoptosis levels were determined in HUVECs and BJs, treated with one therapeutic agent or a combination of them. In the present study, the number of cells in early apoptotic stages following treatment was markedly increased compared with the untreated control samples (Figs. 3 and 4). Vincristine was the most potent inducer of programmed cell death in HUVECs and BJs in vitro compared with the propranolol and bevacizumab treated group $(\mathrm{P}<0.001$; Table II). When using combination treatment, vincristine plus bevacizumab induced the highest levels of apoptosis in HUVECs (Figs. 3G, 4G and 5), in comparison with the BJs where triple therapy was most effective. In addition, the results revealed that among all single drug treatments, with either propranolol, vincristine or bevacizumab, the greatest 
Table $\mathrm{I}_{\text {. }} \mathrm{IC}_{50}$ values determined in HUVECs and BJs treated with propranolol, vincristine and bevacizumab and combinations of the drugs.

$$
\mathrm{IC}_{50}(\mu \mathrm{g} / \mathrm{ml})
$$

Treatment

BJS

$148.32 \pm 0.07^{\text {aaa }}$

$24.81 \pm 0.08^{\text {aaa }}$

$182.70 \pm 0.09^{\mathrm{b}}$

$53.78 \pm 0.06^{\mathrm{b}}$

Propranolol plus vincristine $(10 \mu \mathrm{g} / \mathrm{ml})$

Propranolol plus bevacizumab $(100 \mu \mathrm{g} / \mathrm{ml})$

Vincristine plus bevacizumab $(100 \mu \mathrm{g} / \mathrm{ml})$

Propranolol plus vincristine $(10 \mu \mathrm{g} / \mathrm{ml})$ plus bevacizumab $(100 \mu \mathrm{g} / \mathrm{ml})$
$41.01 \pm 0.05^{\text {aaa }}$

$17.73 \pm 0.10^{\text {aaa }}$
$7.73 \pm 0.11^{\text {aаa }}$
HUVECs

$81.94 \pm 0.06^{\text {aaa }}$

$17.89 \pm 0.07^{\text {аа }}$

$96.91 \pm 0.06^{\mathrm{b}}$

$54.50 \pm 0.06^{\text {aaa }}$

$65.95 \pm 0.03^{\mathrm{b}}$

$9.77 \pm 0.07^{\text {aa }}$

$8.56 \pm 0.04^{\text {aaa }}$

Data are presented as mean \pm standard error. ${ }^{\text {aa }} \mathrm{P}<0.01$; ${ }^{\text {aaa }} \mathrm{P}<0.001$ and ${ }^{\mathrm{b}} \mathrm{P}>0.05 \mathrm{HUVEC}$, human umbilical vein endothelial cell; BJ, CRL-2522 human normal fibroblast; $\mathrm{IC}_{50}$, half inhibitory concentration.
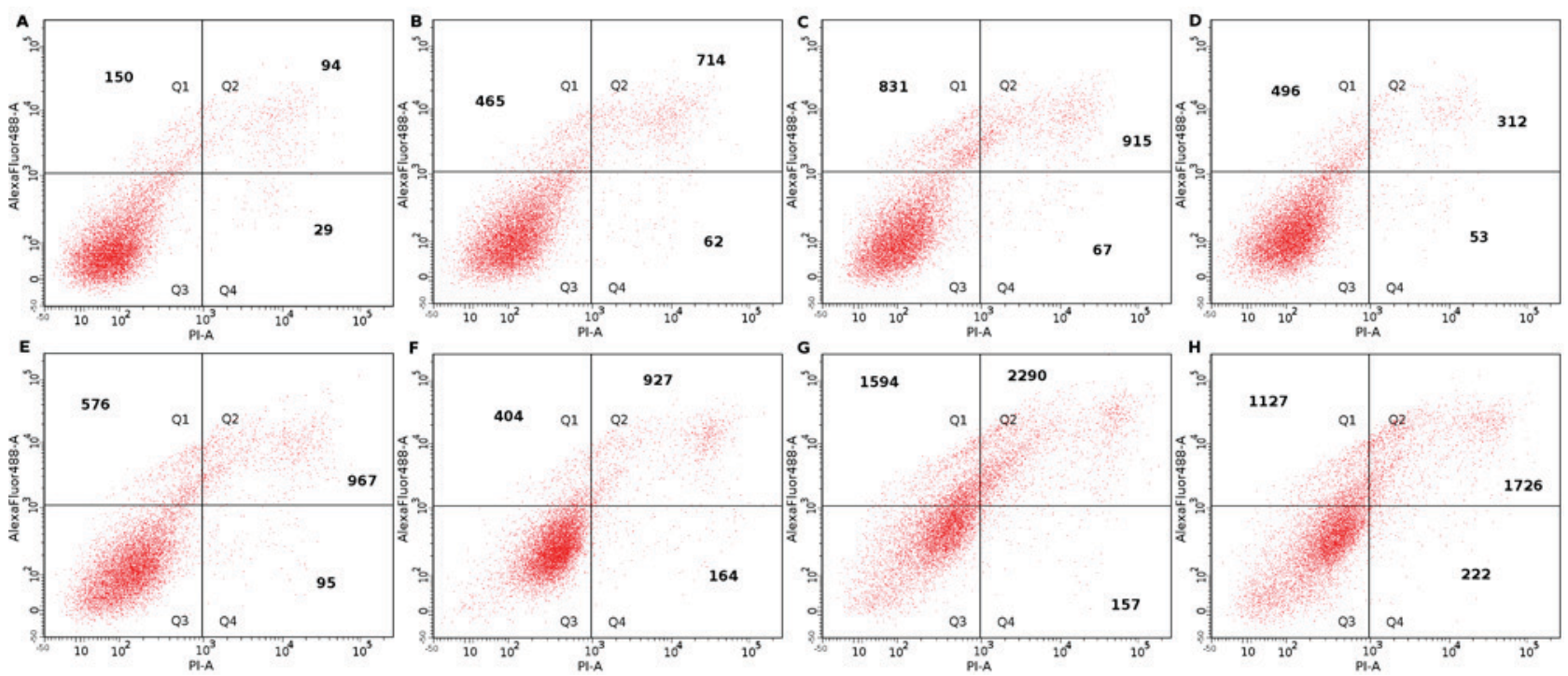

Figure 3. Apoptosis evaluation of HUVECs treated with propranolol, vincristine and bevacizumab and combinations of the drugs. Representative images of flow cytometry-based apoptosis evaluation of HUVECs (A) untreated or treated with (B) propranolol (50 $\mu \mathrm{g} / \mathrm{ml}),(\mathrm{C}) \mathrm{vincristine} \mathrm{(10} \mu \mathrm{g} / \mathrm{ml}),(\mathrm{D})$ bevacizumab $(50 \mu \mathrm{g} / \mathrm{ml}),(\mathrm{E})$ propranolol $(50 \mu \mathrm{g} / \mathrm{ml})$ plus vincristine $(10 \mu \mathrm{g} / \mathrm{ml}),(\mathrm{F})$ propranolol $(50 \mu \mathrm{g} / \mathrm{ml})$ plus bevacizumab $(50 \mu \mathrm{g} / \mathrm{ml}),(\mathrm{G}) \mathrm{vincristine}(10 \mu \mathrm{g} / \mathrm{ml}) \mathrm{plus}$ bevacizumab $(50 \mu \mathrm{g} / \mathrm{ml})$, and $(\mathrm{H})$ propranolol $(50 \mu \mathrm{g} / \mathrm{ml})$ plus vincristine $(10 \mu \mathrm{g} / \mathrm{ml})$ plus bevacizumab $(50 \mu \mathrm{g} / \mathrm{ml})$. HUVECs, human umbilical vein endothelial cell; Q1, quadrant representative of early apoptosis; Q2, quadrant representative of late apoptosis; Q3, quadrant representative of viable cells; Q4, quadrant representative of dead cells.

number of HUVECs found in the late apoptotic stage was when using vincristine $(\mathrm{P}<0.001$; Table II). This observation was similar to the number of HUVECs found in the late apoptotic stage following combination treatment with propranolol plus vincristine. Treatment with vincristine plus bevacizumab was revealed to significantly increase cell numbers in late stage apoptosis compared with mono-treatments, combination treatment of propranolol plus vincristine and triple treatment $(\mathrm{P}<0.05$; Table II and Fig. 5).

In BJs, treatment with vincristine, vincristine plus propranolol and triple treatment increased the number of cells in late stage apoptosis to the greatest extent, when compared with the other cycle cell stages ( $\mathrm{P}<0.05$; Table II; Fig. 5).

Propranolol in combination treatments resulted in increased cell death, compared with combination treatments without Propranolol; however, as subcytotoxic concentrations of propranolol were used, the number of dead cells were lower, indicating increased apoptosis (Figs. 3-5).

Furthermore, the results revealed that there was a correlation between HUVECs and BJs regarding the number of cells in early stage apoptosis at varying treatment options (Spearman r-factor, 0.833; $\mathrm{P}=0.077$; Table II). Correlation was further observed between HUVECs and BJs at late stage apoptosis ( $\mathrm{r}$-factor, 0.743; $\mathrm{P}=0.0288$ ) and with respect to the number of dead cells ( $\mathrm{r}$-factor, 0.895; $\mathrm{P}=0.0109$; Table II).

\section{Discussion}

Infantile hemangiomas are benign vascular tumors that are characterized by a proliferative, involution and involuted phase (3). 

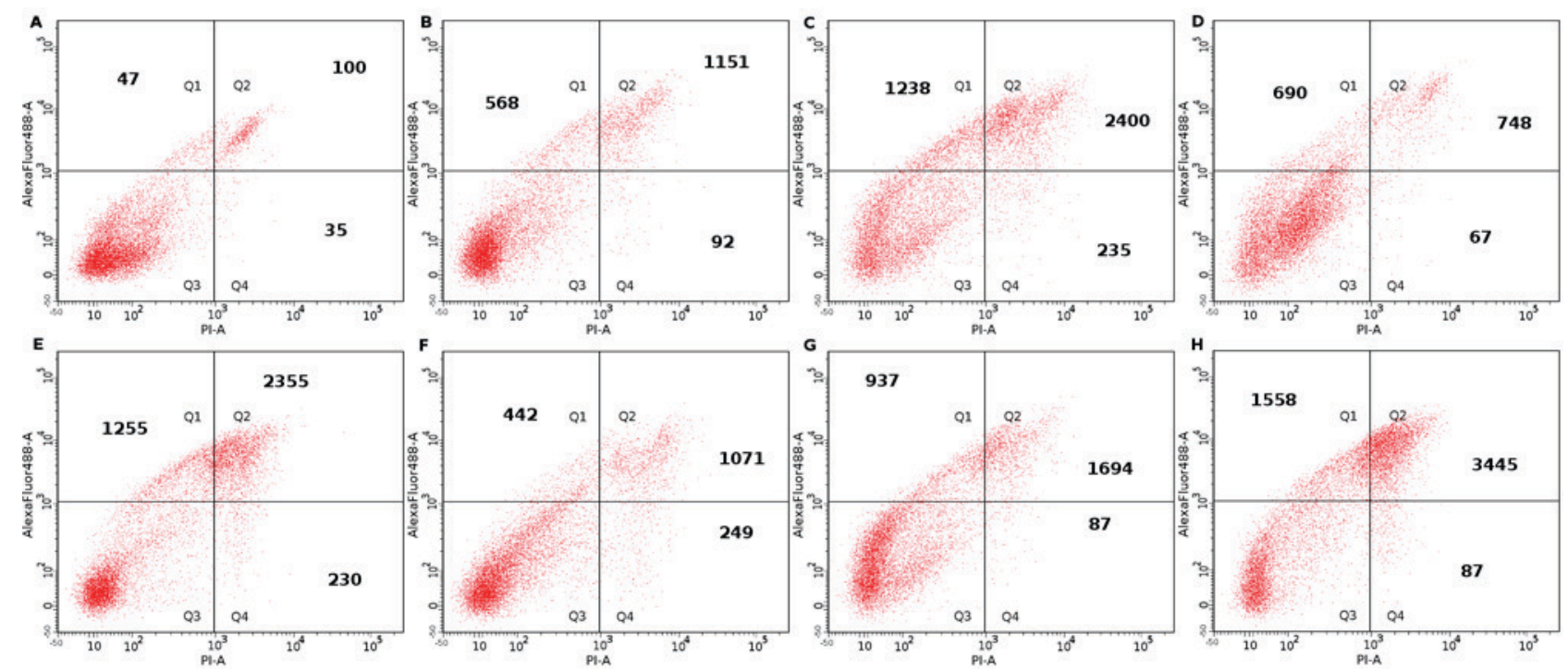

Figure 4. Apoptosis evaluation of BJs treated with propranolol, vincristine and bevacizumab and combinations of the drugs. Representative images of flow cytometry-based apoptosis evaluation of BJs (A) untreated or treated with (B) propranolol (50 $\mu \mathrm{g} / \mathrm{ml}),(\mathrm{C}) \mathrm{vincristine}(10 \mu \mathrm{g} / \mathrm{ml}),(\mathrm{D}) \mathrm{bevacizumab}(50 \mu \mathrm{g} / \mathrm{ml})$, (E) propranolol $(50 \mu \mathrm{g} / \mathrm{ml})$ plus vincristine $(10 \mu \mathrm{g} / \mathrm{ml})$, (F) propranolol $(50 \mu \mathrm{g} / \mathrm{ml})$ plus bevacizumab $(50 \mu \mathrm{g} / \mathrm{ml}),(\mathrm{G}) \mathrm{vincristine}(10 \mu \mathrm{g} / \mathrm{ml}) \mathrm{plus}$ bevacizumab $(50 \mu \mathrm{g} / \mathrm{ml})$, and $(\mathrm{H})$ propranolol $(50 \mu \mathrm{g} / \mathrm{ml})$ plus vincristine $(10 \mu \mathrm{g} / \mathrm{ml})$ plus bevacizumab $(50 \mu \mathrm{g} / \mathrm{ml})$. BJ, CRL-2522 human normal fibroblast; Q1, quadrant representative of early apoptosis; Q2, quadrant representative of late apoptosis; Q3, quadrant representative of viable cells; Q4, quadrant representative of dead cells.

They appear during the first few months of life and proliferate following stimulation by several growth factors, including VEGF and bFGF (5). Following the proliferative phase, hemangiomas rapidly enter the involution phase, where levels of secreted VEGF and bFGF fall and cells undergo apoptosis (16). To date, several studies performed on hemangioma-derived cells (16) and HUVECs (17) have demonstrated an arrest in cell proliferation and subsequent involution of the tumor.

HUVECs represent a primary endothelial cell model (18). Furthermore, HUVECs are similar to hemangioma cells, as they react similarly to endothelial cells present in infantile hemangiomas (19). Several studies were performed using HUVECs to analyze the effects exhibited by Propranolol that result in the involution of hemangiomas $(16,17)$. Further studies used HUVECs as control cell cultures to compare hemangioma-derived stem cells (4) or hemangioma-derived endothelial cells (20). In addition, BJs were used in the present study, to mimic the connective tissue of infantile hemangiomas, composed of fibroblasts, pericytes and mast cells $(3,4,21)$. The present study investigated therapeutic effects of vincristine, propranolol and bevacizumab on HUVEC and BJ cells.

Ji et al (16) demonstrated that propranolol induced apoptosis in hemangioma-derived cells via activation of caspase-3 and -9 , following the intrinsic pathway. Pan et al (22) revealed that propranolol in vitro induces the inhibition of cell cycle progression, concomitantly with decreased nitric oxide and VEGF levels through the downregulation of the phosphoinositide 3-kinase/protein kinase B/endothelial nitric oxide synthase/VEGF signaling pathway. In addition, Tu et al (23) revealed that apoptosis is induced both via the intrinsic and the extrinsic pathway. Ou et al (20) performed a study on hemangioma-model cells (hemEC) that demonstrated that the inhibition of proliferation and induction of apoptosis is associated with downregulation of VEGF receptor 2. Lamy et al (17) investigated effects of propranolol on HUVECs and demonstrated inhibition of cell growth in a dose-dependent manner, which was in line with the results of the present study. This effect was further observed in BJs in the present study, which suggested that the therapeutic effect of propranolol on hemangiomas may be due to the inhibition of growth in the sustaining tissue. However, this observation requires further experimental evidence based specific hemangioma cells for validation. Cell growth inhibition exerted by propranolol was significantly increased in BJs and HUVECs, when treatment was combined with subcytotoxic concentrations of vincristine and bevacizumab, as presented in Figs. 1 and 2. In addition, $\mathrm{IC}_{50}$ values decreased when propranolol was administered together with either the mitosis or the VEGF inhibitors. The cytotoxicity of each drug was stronger in HUVECs compared with BJs; however, the synergistic effect following treatment with propranolol plus the two inhibitors was enhanced in BJs compared with HUVECs.

It has been established that VEGF is one of the most potent growth factors inducing proliferation in hemangiomas (14). However, single treatment with bevacizumab, aVEGF inhibitor, exhibited the weakest effect on viability in the tested cell lines of the current study. This may be associated with the mechanism of action of VEGF inhibitors, which do not directly affect apoptosis levels, but indirectly affect apoptosis by decreasing levels of growth factor, resulting in decreased levels of proliferation and subsequent cell cycle arrest $(24,25)$. However, combination treatment of bevacizumab plus vincristine resulted in a significant increase in apoptosis levels compared with bevacizumab and vincristine single treatments and the determined $\mathrm{IC}_{50}$ significantly decreased in HUVECs for vincristine plus bevacizumab compared with vincristine single treatment, as shown in Table II. This synergy between a direct cytotoxic and a VEGF inhibitor bevacizumab has been established in malignant solid tumors, including lung or 
Table II. Number of apoptotic and dead HUVECs and BJs treated with propranolol, vincristine and bevacizumab and combinations of the drugs, determined by flow cytometry.

A, Early apoptotic cells within a population of 10,000 cells

\begin{tabular}{|c|c|c|c|c|}
\hline Treatment & HUVECs & BJs & $\mathrm{R}$ & P-value \\
\hline Untreated & $150 \pm 3$ & $47 \pm 4$ & & \\
\hline Propranolol & $465 \pm 14^{\mathrm{c}}$ & $568 \pm 2^{\mathrm{c}}$ & & \\
\hline Vincristine & $831 \pm 6^{\mathrm{c}}$ & $1238 \pm 34^{\mathrm{c}}$ & & \\
\hline Bevacizumab & $496 \pm 27^{c}$ & $690 \pm 31^{\mathrm{c}}$ & & \\
\hline Propranolol plus vincristine $(10 \mu \mathrm{g} / \mathrm{ml})$ & $576 \pm 31^{\mathrm{c}}$ & $1255 \pm 58^{\mathrm{c}}$ & & \\
\hline Propranolol plus bevacizumab $(50 \mu \mathrm{g} / \mathrm{ml})$ & $404 \pm 12^{c}$ & $442 \pm 13^{c}$ & & \\
\hline Vincristine plus bevacizumab $(50 \mu \mathrm{g} / \mathrm{ml})$ & $1,594 \pm 53^{\mathrm{c}}$ & $937 \pm 8^{c}$ & & \\
\hline Propranolol plus vincristine $(10 \mu \mathrm{g} / \mathrm{ml})$ plus bevacizumab $(50 \mu \mathrm{g} / \mathrm{ml})$ & $1,127 \pm 41^{\mathrm{c}}$ & $1558 \pm 4^{c}$ & 0.833 & 0.077 \\
\hline
\end{tabular}

B, Late apoptotic cells within a population of 10,000 cells

\begin{tabular}{|c|c|c|c|c|}
\hline Treatment & HUVECs & BJs & $\mathrm{R}$ & P-value \\
\hline Untreated & $94 \pm 2$ & $100 \pm 11$ & & \\
\hline Propranolol & $714 \pm 8^{c}$ & $1151 \pm 98^{c}$ & & \\
\hline Vincristine & $915 \pm 58^{c}$ & $2400 \pm 69^{c}$ & & \\
\hline Bevacizumab & $312 \pm 10^{\mathrm{b}}$ & $748 \pm 4^{c}$ & & \\
\hline Propranolol plus vincristine $(10 \mu \mathrm{g} / \mathrm{ml})$ & $967 \pm 7^{c}$ & $2355 \pm 57^{\mathrm{c}}$ & & \\
\hline Propranolol plus bevacizumab $(50 \mu \mathrm{g} / \mathrm{ml})$ & $927 \pm 44^{c}$ & $1071 \pm 14^{\mathrm{c}}$ & & \\
\hline Vincristine plus bevacizumab $(50 \mu \mathrm{g} / \mathrm{ml})$ & $2290 \pm 86^{c}$ & $1694 \pm 50^{c}$ & & \\
\hline Propranolol plus vincristine $(10 \mu \mathrm{g} / \mathrm{ml})$ plus bevacizumab $(50 \mu \mathrm{g} / \mathrm{ml})$ & $1726 \pm 22^{c}$ & $3445 \pm 27^{c}$ & 0.743 & 0.0288 \\
\hline \multicolumn{5}{|l|}{ C, Dead cells within a population of 10,000 cells } \\
\hline Treatment & HUVECs & BJs & $\mathrm{R}$ & P-value \\
\hline Untreated & $29 \pm 3$ & $35 \pm 2$ & & \\
\hline Propranolol & $62 \pm 6^{\mathrm{d}}$ & $92 \pm 16^{\mathrm{a}}$ & & \\
\hline Vincristine & $67 \pm 9^{d}$ & $235 \pm 23^{c}$ & & \\
\hline Bevacizumab & $53 \pm 1^{\mathrm{d}}$ & $67 \pm 9^{d}$ & & \\
\hline Propranolol plus vincristine $(10 \mu \mathrm{g} / \mathrm{ml})$ & $95 \pm 4^{\mathrm{b}}$ & $230 \pm 1^{\mathrm{c}}$ & & \\
\hline Propranolol plus bevacizumab $(50 \mu \mathrm{g} / \mathrm{ml})$ & $164 \pm 10^{c}$ & $249 \pm 27^{\mathrm{c}}$ & & \\
\hline Vincristine plus bevacizumab $(50 \mu \mathrm{g} / \mathrm{ml})$ & $157 \pm 12^{c}$ & $87 \pm 7^{\mathrm{a}}$ & & \\
\hline Propranolol plus vincristine $(10 \mu \mathrm{g} / \mathrm{ml})$ plus bevacizumab $(50 \mu \mathrm{g} / \mathrm{ml})$ & $222 \pm 32^{c}$ & $267 \pm 22^{c}$ & 0.895 & 0.0109 \\
\hline
\end{tabular}

Data are presented as mean \pm standard deviation. ${ }^{\mathrm{a}} \mathrm{P}<0.05$; ${ }^{\mathrm{b}} \mathrm{P}<0.01 ;{ }^{\mathrm{c}} \mathrm{P}<0.001$ and ${ }^{\mathrm{d}} \mathrm{P}>0.05$ vs. untreated. $\mathrm{R}$, Spearman correlation coefficient with $95 \%$ confidence interval; HUVEC, human umbilical vein endothelial cell; BJ, CRL-2522 human normal fibroblast.

colon cancer and has been revealed to reduce VEGF levels and enhance cytotoxic effects of the chemotherapeutical agents, which subsequently results in improved therapeutic outcomes $(26,27)$. As a result, cell growth may not only be dependent on growth factors, but may be associated with numerous other mechanisms, including mitosis inhibition. A similar effect was observed in BJs. Liu et al (28) demonstrated that combination treatment using bevacizumab and TRC105, two angiogenesis inhibitors with varying mechanisms of action, suppresses HUVEC growth to a greater extent when compared with single treatments. The results of the present study demonstrated that using a therapeutic approach based on different mechanism of action increased the efficacy in tumor arrest and involution, when compared with treatment with two agents that have a similar mechanism. Effects of bevacizumab may be increased in in vivo studies, particularly when combined with other treatments, compared with the in vitro model due to the increased secretion of growth factor observed in viable cells; however, further experimental proof is required. Hayot et al (29) investigated several agents, including vincristine, vinblastine, vindesine and vinorelbine, to determine their effects on HUVECs and demonstrated that 

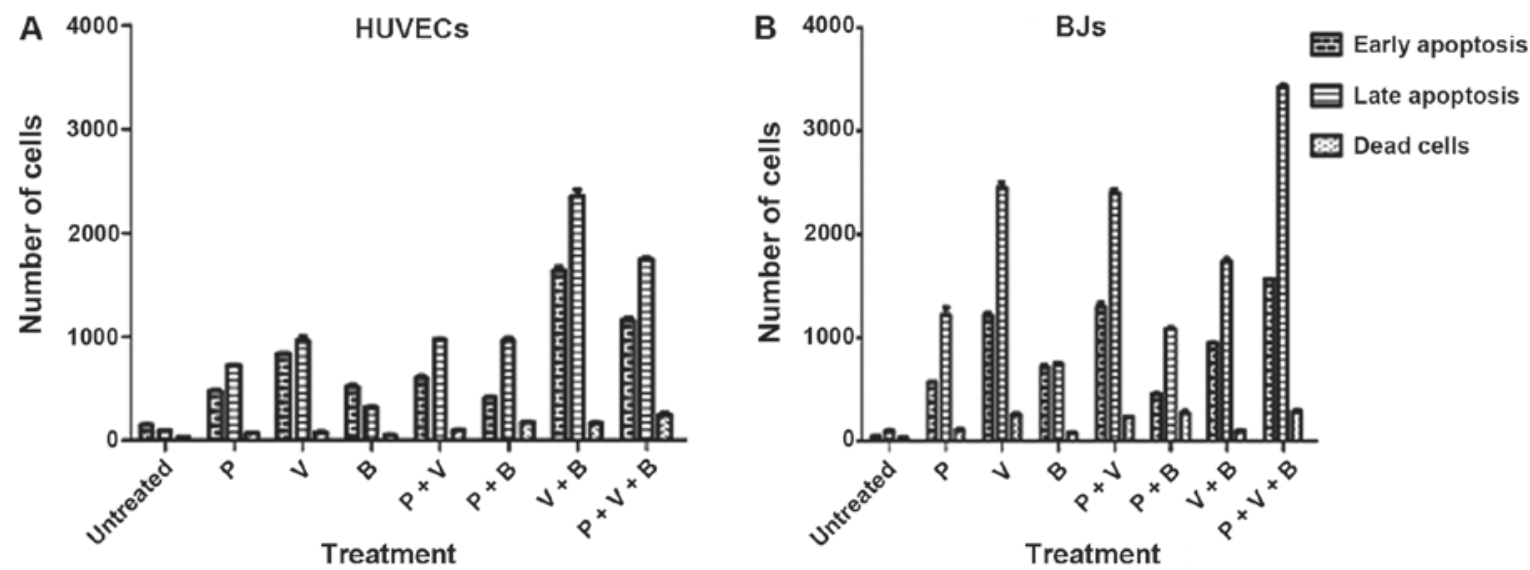

Figure 5. Quantitative evaluation of apoptosis in HUVECs and BJs treated with propranolol, vincristine and bevacizumab and combinations of the drugs. Number early and late apoptotic and dead cells determined by flow cytometry using (A) HUVECs and (B) BJs treated with propranolol (50 $\mu \mathrm{g} / \mathrm{ml})$, vincristine $(10 \mu \mathrm{g} / \mathrm{ml})$ and bevacizumab $(50 \mu \mathrm{g} / \mathrm{ml})$ and combinations of the drugs. Values are per population of 10,000 cells. HUVEC, human umbilical vein endothelial cell; BJ, CRL-2522 human normal fibroblast; P, propranolol; V, vincristine; B, bevacizumab.

vincristine has an antiangiogenic effect, even when administered at non-cytotoxic concentrations $(10 \mu \mathrm{g} / \mathrm{ml})$. The present study demonstrated marked cytotoxic effects of vincristine administered at $100 \mu \mathrm{g} / \mathrm{ml}$ in single or at $10 \mu \mathrm{g} / \mathrm{ml}$ in combination treatment with bevacizumab and/or propranolol. The results suggested that the cytotoxic effects of vincristine, via antiangiogenesis or direct cytotoxicity, were dependent on the concentration. Consequently the question remains, whether the concentration of vincristine administered in vivo has antiangiogenic or directly cytotoxic effects, suggesting that the range of vincristine administrable to patients is large and adaptable to patient needs. However, further investigations in this direction are required.

Following treatment, early apoptosis can occur within $30 \mathrm{~min}$ or thereafter, depending on cell and exposure type (30). In the current study, cells in early and late apoptosis were differentiated. In HUVECs, combination of vincristine and bevacizumab increased cells numbers in early and late stage apoptosis compared with triple treatment with propranolol, vincristine and bevacizumab. In BJs, triple treatment with propranolol, vincristine and bevacizumab exhibited the most pronounced apoptosis induction compared with all other treatment options. This difference between the cell lines may be due to varying proliferation rates and longer doubling times of BJs.

Regarding monotherapy, vincristine was revealed to be the most potent therapeutic agent in BJs and HUVECs inducing early and late stage apoptosis compared with the other single treatment regiments. The next best results were obtained with propranolol, which induced higher levels on late apoptosis compared with cells in early apoptosis. Treatment with bevacizumab plus vincristine exhibited a greater combinatory therapeutic effect compared with propranolol plus vincristine. This may be due to the similar mechanism of action exhibited by propranolol and vincristine, while bevacizumab and vincristine exhibit varying mechanisms of action. Future studies are required to elucidate the antiangiogenic mechanism of the combination of these drugs.

Patients with infantile hemangioma require prolonged treatment with propranolol to achieve tumor regression, which may be due to the fact that propranolol predominantly induces late apoptosis, as was shown in our study. In hemangiomas that are difficult to treat or life threatening and where rapid therapeutic effects are required, vincristine is used (5). The various combinations of the drugs used in the current study require further investigation on specific hemangioma cell cultures or tissues, to evaluate novel therapeutic strategies for patients with infantile hemangiomas.

In conclusion, a marked synergistic effect on HUVECs and BJs was observed following administration of propranolol with bevacizumab and vincristine. Apoptosis was induced by the various treatments trialed in the present study; however, triple treatment exhibited the most marked increase in apoptosis in BJs and vincristine plus bevacizumab exhibited the strongest effect in HUVECs. The results of the present study may constitute a basis for novel drug testing and drug repurposing regarding the treatment of infantile hemangiomas.

\section{Acknowledgements}

The authors would like to thank Dr Olga Soritau (Oncology Institute 'I. Chiricuță', Cluj-Napoca, Romania) for supplying the HUVECs.

\section{Funding}

The current study was supported by the framework of PCD 2016 of the University of Medicine and Pharmacy 'Iuliu Hatieganu' (Cluj-Napoca, Romania; grant no. 7690/12/15.04.2016).

\section{Availability of data and materials}

All data generated or analyzed during the present study are included in this published article.

\section{Authors' contributions}

MB generated and analyzed data and contributed to the writing of the article. EFF designed the cytotoxicity studies, performed the experiments and revised the manuscript. OVB 
documented research and conceived and designed the current study. MC designed and performed the flow cytometry analysis, and elaborated and revised the manuscript. GP and CLB were involved in the drafting of the manuscript and its critical revision for important intellectual content. AT coordinated the study, supervised its progress and approved the final version of the article for publication. All authors read and approved the final version of the manuscript.

\section{Ethics approval and consent to participate}

Not applicable.

\section{Patient consent for publication}

Not applicable.

\section{Competing interests}

The authors declare that they have no competing interests.

\section{References}

1. Rotter A and de Oliveira ZNP: Infantile hemangioma: Pathogenesis and mechanisms of action of propranolol. J Dtsch Dermatol Ges 15: 1185-1190, 2017.

2. Storch $\mathrm{CH}$ and Hoeger PH: Propranolol for infantile haemangiomas: Insights into the molecular mechanisms of action. $\mathrm{Br} \mathrm{J}$ Dermatol 163: 269-274, 2010.

3. Schwartz RA, Sidor MI, Musumeci ML, Lin RL and Micali G: Infantile haemangiomas: A challenge in paediatric dermatology. J Eur Acad Dermatol Venereol 24: 631-638, 2010.

4. Harbi S, Wang R, Gregory M, Hanson N, Kobylarz K, Ryan K, Deng Y, Lopez P, Chiriboga L and Mignatti P: Infantile hemangioma originates from a dysregulated but not fully transformed multipotent stem cell. Sci Rep 6: 35811, 2016.

5. Léauté-Labrèze C: Infantile hemangioma: Update and treatment. Arch Pediatr 20: 517-522, 2013 (In French).

6. Léauté-Labrèze C, Dumas de la Roque E, Hubiche T, Boralevi F, Thambo JB and Taïeb A: Propranolol for severe hemangiomas of infancy. N Engl J Med 358: 2649-2651, 2008.

7. Raphael MF, Breur JM, Vlasveld FA, Elbert NJ, Liem YT, Kon M, Breugem CC and Pasmans SG: Treatment of infantile hemangiomas: Therapeutic options in regard to side effects and adverse events-a review of the literature. Expert Opin Drug Saf 15: 199-214, 2016.

8. Wasserman JD, Mahant S, Carcao M, Perlman K and Pope E: Vincristine for successful treatment of steroid-dependent infantile hemangiomas. Pediatrics 135: e1501-e1505, 2015.

9. Yamashita-Kashima Y, Fujimoto-Ouchi K, Yorozu K, Kurasawa M, Yanagisawa M, Yasuno H and Mori K: Biomarkers for antitumor activity of bevacizumab in gastric cancer models. BMC Cancer 12: 37, 2012.

10. Pourazizi M, Kabiri S and Abtahi-Naeini B: Intralesional bevacizumab (Avastin ${ }^{\circledR}$ ) as a novel addition to infantile hemangioma management: A medical hypothesis. J Res Pharm Pract 6: 190-191, 2017.

11. Stiles J, Amaya C, Pham R, Rowntree RK, Lacaze M, Mulne A, Bischoff J, Kokta V, Boucheron LE, Mitchell DC and Bryan BA: Propranolol treatment of infantile hemangioma endothelial cells: A molecular analysis. Exp Ther Med 4: 594-604, 2012.

12. Hein $M$ and Graver S: Tumor cell response to bevacizumab single agent therapy in vitro. Cancer Cell Int 13: 94, 2013.

13. Chao MW, Lai MJ, Liou JP, Chang YL, Wang JC, Pan SL and Teng CM: The synergic effect of vincristine and vorinostat in leukemia in vitro and in vivo. J Hematol Oncol 8: 82, 2015.
14. Fischer-Fodor E, Mot A, Deac F, Arkosi $M$ and Silaghi-Dumitrescu R: Towards hemerythrin-based blood substitutes: Comparative performance to hemoglobin on human leukocytes and umbilical vein endothelial cells. J Biosci 36: 215-221, 2011.

15. Ceballos-Torres J, Virag P, Cenariu M, Prashar S, Fajardo M, Fischer-Fodor E and Gómez-Ruiz S: Anti-cancer applications of titanocene-functionalised nanostructured systems: An insight into cell death mechanisms. Chemistry 20: 10811-10828, 2014.

16. Ji Y, Li K, Xiao X, Zheng S, Xu T and Chen S: Effects of propranolol on the proliferation and apoptosis of hemangioma-derived endothelial cells. J Pediatr Surg 47: 2216-2223, 2012.

17. Lamy S, Lachambre MP, Lord-Dufour S and Béliveau R: Propranolol suppresses angiogenesis in vitro: Inhibition of proliferation, migration, and differentiation of endothelial cells. Vascul Pharmacol 53: 200-208, 2010.

18. Bouis D, Hospers GA, Meijer C, Molema G and Mulder NH: Endothelium in vitro: A review of human vascular endothelial cell lines for blood vessel-related research. Angiogenesis 4: 91-102, 2001

19. Zou HX, Jia J, Zhang WF, Sun ZJ and Zhao YF: Propranolol inhibits endothelial progenitor cell homing: A possible treatment mechanism of infantile hemangioma. Cardiovasc Pathol 22: 203-210, 2013.

20. Ou JM, Yu ZY, Qiu MK, Dai YX, Dong Q, Shen J, Wang XF, Liu YB, Quan ZW and Fei ZW: Knockdown of VEGFR2 inhibits proliferation and induces apoptosis in hemangioma-derived endothelial cells. Eur J Histochem 58: 2263, 2014.

21. Ritter MR, Butschek RA, Friedlander M and Friedlander SF: Pathogenesis of infantile haemangioma: New molecular and cellular insights. Expert Rev Mol Med 9: 1-19, 2007.

22. Pan WK, Li P, Guo ZT, Huang Q and Gao Y: Propranolol induces regression of hemangioma cells via the down-regulation of the PI3K/Akt/eNOS/VEGF pathway. Pediatr Blood Cancer 62: 1414-1420, 2015.

23. Tu JB, Ma RZ, Dong Q, Jiang F, Hu XY, Li QY, Pattar P and Zhang H: Induction of apoptosis in infantile hemangioma endothelial cells by propranolol. Exp Ther Med 6: 574-578, 2013.

24. Margolin K, Gordon MS, Holmgren E, Gaudreault J, Novotny W, Fyfe G, Adelman D, Stalter S and Breed J: Phase Ib trial of intravenous recombinant humanized monoclonal antibody to vascular endothelial growth factor in combination with chemotherapy in patients with advanced cancer: Pharmacologic and long-term safety data. J Clin Oncol 19: 851-856, 2001.

25. Jain RK: Tumor angiogenesis and accessibility: Role of vascular endothelial growth factor. Semin Oncol 29 (6 Suppl 16): S3-S9, 2002.

26. Sandler A, Gray R, Perry MC, Brahmer J, Schiller JH, Dowlati A, Lilenbaum R and Johnson DH: Paclitaxel-carboplatin alone or with bevacizumab for non-small-cell lung cancer. N Engl J Med 355: 2542-2550, 2006.

27. Kabbinavar F, Irl C, Zurlo A and Hurwitz H: Bevacizumab improves the overall and progression-free survival of patients with metastatic colorectal cancer treated with 5-fluorouracil-based regimens irrespective of baseline risk. Oncology 75: 215-223, 2008.

28. Liu Y, Tian H, Blobe GC, Theuer CP, Hurwitz HI and Nixon AB: Effects of the combination of TRC105 and bevacizumab on endothelial cell biology. Invest New Drugs 32: 851-859, 2014.

29. Hayot C, Farinelle S, De Decker R, Decaestecker C, Darro F, Kiss $\mathrm{R}$ and Van Damme M: In vitro pharmacological characterizations of the anti-angiogenic and anti-tumor cell migration properties mediated by microtubule-affecting drugs, with special emphasis on the organization of the actin cytoskeleton. Int J Oncol 21: 417-425, 2002.

30. Anguissola S, Garry D, Salvati A, O'Brien PJ and Dawson KA: High content analysis provides mechanistic insights on the pathways of toxicity induced by amine-modified polystyrene nanoparticles. PLoS One 9: e108025, 2014.

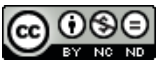

This work is licensed under a Creative Commons Attribution-NonCommercial-NoDerivatives 4.0 International (CC BY-NC-ND 4.0) License. 